\title{
The impact of depression on surgical outcome in Chiari malformation type I: an assessment based on the Chicago Chiari Outcome Scale
}

\author{
James Feghali, MD, ${ }^{1}$ Yuxi Chen, BS, ${ }^{2}$ Yangyiran Xie, BS, ${ }^{2}$ Christopher Chen, ${ }^{3}$ and Judy Huang, MD ${ }^{1}$ \\ 1Department of Neurosurgery, Johns Hopkins University School of Medicine, Baltimore; ${ }^{2}$ Krieger School of Arts and Sciences, \\ Johns Hopkins University, Baltimore; and ${ }^{3}$ Robert H. Smith School of Business, University of Maryland, College Park, Maryland
}

\begin{abstract}
OBJECTIVE The effect of depression on outcomes in Chiari malformation type I (CM-1) is unclear. The authors sought to determine whether depression affects outcome in a surgical cohort of CM-1 patients by using a validated outcome assessment tool, the Chicago Chiari Outcome Scale (CCOS).

METHODS The authors performed a retrospective analysis of a prospectively maintained database of 149 adult CM-1 patients undergoing suboccipital decompression with duraplasty and cranioplasty. Baseline presentation characteristics and composite as well as subcomponent CCOS scores at last follow-up were compared between depressed and nondepressed patients. Outcome comparisons included both a univariable analysis and a logistic regression model adjusting for several covariates.
\end{abstract}

RESULTS The prevalence of depression in the study cohort was 28\% (41/149). Baseline demographic and imaging characteristics were similar between the 2 patient groups. Dizziness $(p=0.019)$ and imbalance $(p=0.015)$ were significantly more common among depressed patients, but clinical symptoms and severity were otherwise comparable. On univariable analysis, depressed patients were significantly less likely to experience improvement in pain symptoms (OR $0.14,95 \% \mathrm{Cl} 0.03-0.61, p=0.003$ ) and functionality (OR $0.17,95 \% \mathrm{Cl} 0.03-0.99, p=0.049)$. No significant difference was identified in complications, nonpain symptom improvement, or overall composite CCOS improvement. Similar results were obtained on multivariable analysis controlling for several covariates.

CONCLUSIONS Depression is independently associated with poor surgical outcome in adult CM-1 patients, namely when evaluating improvement in pain symptoms and functionality. Optimizing the management of depression preoperatively and ensuring follow-up for psychiatric comorbidity in the postoperative period may possibly lead to improved outcomes.

https://thejns.org/doi/abs/10.3171/2020.2.SPINE2069

KEYWORDS Arnold-Chiari malformation; depression; decompression; surgical; cervical

I N 1891, the Austrian pathologist Hans Chiari first described what came to be known today as Arnold-Chiari malformations. ${ }^{1}$ He defined one of the variants as a "peglike elongation of tonsils and medial divisions of the inferior lobes of the cerebellum into cone shaped projections, which accompany the medulla oblongata into the spinal canal."' Now known as Chiari malformation type I (CM-1), this disease is diagnosed in as many as $1 \%$ of patients undergoing MRI when purely radiological criteria are used. ${ }^{2}$ CM-1 constitutes a common neurosurgical condition with often debilitating symptoms that usually present in the 2nd or 3 rd decade of life. There remains wide variation in the indications and techniques recommended for the surgical management of CM- $1,{ }^{3}$ mostly due to poor understanding of disease pathophysiology, natural history, and response to surgery. Although several factors have been investigated as potential predictors of surgical outcome, ${ }^{4,5}$ the influence of mental health in general, and depression in particular, on outcome remains unclear. Given the proven impact depression has on survival and outcome in other neurological diseases such as glioma and stroke, ${ }^{6,7}$ we sought to determine whether the same association exists in CM-1.

\section{Methods}

\section{Patient Population}

Patient data were obtained from an institutional review board-approved database with prospectively collected information on adult CM-1 patients presenting to our institution between January 1, 2006, and December 31, 2018.

ABBREVIATIONS $\mathrm{CCOS}=$ Chicago Chiari Outcome Scale; $\mathrm{CM}-1=$ Chiari malformation type $\mathrm{I} ; \mathrm{CSI}=$ Chiari Severity Index .

SUBMITTED January 16, 2020. ACCEPTED February 19, 2020.

INCLUDE WHEN CITING Published online April 24, 2020; DOI: 10.3171/2020.2.SPINE2069. 
Patient consent was not needed, as this was a retrospective study with no patient contact or intervention. The clinical diagnosis of CM-1 was defined as at least $3 \mathrm{~mm}$ of herniation of the tonsillar tip on MRI, along with symptoms attributable to CM-1, including any combination of the following symptoms: headache, neck pain, imbalance, weakness, visual symptoms, tinnitus, dysphagia, paresthesias, and numbness. ${ }^{8}$ Patients with connective tissue disease (e.g., Ehlers-Danlos syndrome), pseudotumor cerebri, or basilar invagination were excluded in addition to patients undergoing reoperation procedures.

\section{Baseline Presentation Characteristics}

Data on demographic, clinical, and imaging variables were retrieved from electronic patient records. Age was recorded at the time of diagnosis with $\mathrm{CM}-1$, and race was initially categorized into 3 groups: white, black, and other. Other baseline characteristics that were recorded include sex, family history of CM-1, BMI, symptom duration (measured from the beginning of clinically impairing symptoms until diagnosis), trauma history, and regular analgesic use, defined as reported use of an analgesic (almost daily), as prescribed, upon initial evaulation. As has been described previously, ${ }^{9}$ depression was recorded as present when the medical chart reported the presence of either 1) a major depressive episode over the patient's lifetime or 2) antidepressant intake within the last 6 months with a mention of depression (antidepressant intake for other reasons like headache or neuropathy was excluded). Imaging characteristics included the degree of tonsillar tip herniation (millimeters from McRae's line), the presence of a syrinx, and the presence of peg-shaped tonsils. Clinical presentation variables that were noted included headache characteristics, neck pain, numbness, paresthesias, syncope, concentration disturbance, memory issues, hearing problems, tinnitus, visual problems, dysphagia, dizziness, vertigo, nausea, imbalance, weakness, speech disturbance, fatigue, hyperreflexia, and gait disturbance. The Chiari Severity Index (CSI) was also calculated for every patient based on the combination of syrinx properties and clinical symptoms. ${ }^{10}$

\section{Surgical Procedure}

All of the operations were performed by the senior author after appropriate consent was obtained from patients. Surgery was offered after a comprehensive assessment of clinical presentation, symptom interference with daily functioning and quality of life, imaging findings, and CSF flow studies. In general, surgery was offered to patients with clinically significant symptoms that interfered with daily life and all patients with syringomyelia. All patients underwent a uniform surgical procedure consisting of suboccipital craniectomy with combined $\mathrm{C} 1$ laminectomy, duraplasty, and cranioplasty. In patients presenting with a syrinx, arachnoid dissection was also performed until CSF was noted to emanate from the fourth ventricle. When bulky tonsils demonstrating significant herniation were encountered, tonsillar cauterization was performed.

\section{Outcome Assessment}

During patient follow-up, the occurrence of proce- dure-related complications including CSF leak, pseudomeningocele, chemical meningitis, surgical site infection, wound dehiscence, and the need for operative exploration was recorded. At last follow-up, the degree of improvement in pain symptoms, nonpain symptoms, and functional status was noted. Then, the Chicago Chiari Outcome Scale (CCOS), a validated tool for assessing postoperative outcome in Chiari type I patients, was used to calculate outcomes on a continuous 16-point scale (4, incapacitated outcome; 16, excellent outcome), as described by Aliaga and colleagues. ${ }^{11}$ Briefly, points were calculated for every 1 of the 4 CCOS subcomponents: pain symptoms (1-4 points), nonpain symptoms (1-4 points), functionality (1-4 points), and complications (1-4 points). The composite CCOS score was obtained by adding scores from all 4 individual subcomponents. Although several methods of assessing decompression outcomes in CM-1 patients exist, the CCOS was used since it has been rigorously tested in several cohorts and demonstrated adequate validity and reliability. ${ }^{12,13}$

\section{Statistical Analysis}

Baseline characteristics at the first clinic visit were summarized using descriptive statistics (n [\%] for categorical variables and mean \pm SD for continuous variables). Comparisons were made between patients with and without depression. The independent samples t-test was used for continuous variables, and the chi-square and Fisher exact tests were used for categorical variables. The 4 CCOS domains were each dichotomized into favorable (score of 3 or 4) or unfavorable (score of 1 or 2) outcome, and a favorable overall outcome was defined as a total CCOS score ranging from 13 to 16 , as has been described previously. ${ }^{4,11}$ Since depression may affect outcome in any 1 of the 4 CCOS domains, univariable analysis was performed to evaluate potential associations between baseline variables and any of the 4 CCOS domains as well as the composite CCOS score. Since the CSI already includes several key clinical variables such as headache and myelopathy symptoms, clinical symptoms were only included in the analysis if they differed significantly between depressed and nondepressed patients (possible confounders). The multivariable analysis evaluated all demographic variables in addition to the presence of a syrinx and variables with a $\mathrm{p}$ value $<0.1$ in any comparison at the univariable level. We respected the subjects-to-variables rule of 10 to avoid adding an excess of predictors to the model. ${ }^{5}$ Statistical analyses were performed using SPSS software (version 25.0; IBM Corp.) with statistical significance set at $\mathrm{p}$ $<0.05$.

\section{Results}

\section{Patients}

Our database consisted of 219 adult CM-1 patients, of whom 149 (68\%) underwent suboccipital decompression and constituted the study cohort. The mean patient age was $35.1 \pm 11.5$ years, and most patients (122/149) were female. Concerning race, 68\% (102/149) of patients were white, 23\% (34/149) were black, and 9\% (13/149) belonged to other ethnicities. The mean BMI was $30.9 \pm 8.3 \mathrm{~kg} / \mathrm{m}^{2}$, 
and $7 \%(11 / 149)$ of patients had a positive family history of CM-1.

\section{Baseline Characteristics}

The overall prevalence of depression in this adult CM-1 cohort was $28 \%$ (41/149), and most patients (139/149) had tonsillar ectopia exceeding $5 \mathrm{~mm}$. There were 5 patients with a documented diagnosis of a major depressive episode, and all were taking an antidepressant medication at presentation. The comparison of baseline characteristics between depressed and nondepressed CM-1 patients is provided in Table 1 . The 2 patient groups were largely comparable in baseline demographic variables, including age $(p=0.369)$, sex $(p=0.247)$, and race $(p=0.351)$. There were no significant differences in trauma history $(p$ $=0.566)$, analgesic use $(\mathrm{p}=0.832)$, and narcotic intake ( $\mathrm{p}$ $=0.247$ ). Most patients had a CSI grade of 1 or 2 with no significant difference in distribution between depressed and nondepressed patients $(\mathrm{p}=0.482)$. The patients were also well balanced in terms of radiological variables, with most patients demonstrating limitation of CSF flow. There was an average of 3.8 years between the beginning of impairing symptoms and diagnosis, with no significant difference between the 2 groups $(\mathrm{p}=0.753)$. Dizziness $(\mathrm{p}=$ $0.019)$ and problems with balance $(p=0.015)$ were significantly more common among depressed patients, but clinical symptoms were otherwise similar between the groups.

\section{Surgical Outcome}

After a mean follow-up period of $1.9 \pm 1.9$ years following surgery, most patients demonstrated improvement in pain symptoms $(122 / 149,82 \%)$, nonpain symptoms $(130 / 149,87 \%)$, and functionality $(143 / 149,96 \%)$. Of all the patients, 16\% (24/149) had procedure-related complications, with surgical site infection being the most common $(12 / 24)$. A summary of the complications can be found in Fig. 1. Many (14/24) of the complications were transient, and hence most patients $(136 / 149,91 \%)$ had transient or no complications. Posterior fossa reexploration was necessary in 4 patients: 2 had indolent cranioplasty infections, 1 had a large 7-cm pseudomeningocele, and 1 patient required expansion of a decompressive craniectomy due to return of symptoms.

Depressed patients had worse outcomes across all CCOS domains, with statistically significant differences in pain and functionality improvement (Fig. 2). The univariable analysis evaluating favorable outcomes across the CCOS domains can be found in Table 2. Concerning pain symptoms, white patients were significantly less likely to experience improvement (OR 0.14, 95\% CI 0.03-0.61, $\mathrm{p}=$ 0.003 ). This was also true for depressed patients (OR 0.39, $95 \%$ CI $0.16-0.93, p=0.033$ ). Concerning nonpain symptoms, there was no significant association between depression and improvement (OR 0.61, 95\% CI 0.22-1.67, p = $0.330)$. The CSI was the only factor significantly associated with nonpain symptom improvement, whereby grade 2 patients were less likely to improve than grade 1 patients (OR $0.28,95 \%$ CI $0.09-0.84, p=0.024)$. Concerning functionality, depressed patients were significantly less likely to improve (OR $0.17,95 \%$ CI $0.03-0.99, \mathrm{p}=0.049)$.
In terms of procedure-related complications, the rates of favorable outcome were almost identical among depressed $(91 \%)$ and nondepressed $(90 \%)$ patients $(\mathrm{p}=0.753)$. Patients with peg-shaped tonsils were less likely to have a favorable complication profile (OR 0.13, 95\% CI 0.03-0.62, $\mathrm{p}=0.003)$. For the relationship between the CSI and overall improvement, there was a decrease in the likelihood of improvement with increasing grade (85\% of patients with grade 1 improved, $75 \%$ with grade 2 , and $70 \%$ with grade 3 ), but these results were not statistically significant ( $\mathrm{p}=$ 0.301 ). Similar results were obtained in the multivariable analysis (Table 3), whereby depressed patients were less likely to experience improvement in pain symptoms (OR $0.36,95 \%$ CI $0.14-0.97, p=0.044)$ and functionality (OR $0.05,95 \% \mathrm{CI}, 0.01-0.69, \mathrm{p}=0.026)$.

\section{Discussion}

The link between depression and surgical outcome in adult CM-1 patients remains unclear. Because CM-1 is a relatively common disease with impairing symptoms that impact quality of life, it is important to evaluate whether mental health affects outcome, especially given the paucity of knowledge regarding outcome predictors in this disease.

\section{Depression Prevalence: The General Population and CM-1 Patients}

A meta-analysis looking at depression among residents of 30 countries between 1994 and 2014 reported an aggregate point prevalence of depression of $12.9 \% .{ }^{14}$ Another recent epidemiological study reported a 10.4\% 12-month prevalence of depression according to Diagnostic and Statistical Manual of Mental Disorders (DSM-5) major depressive disorder criteria. ${ }^{15}$ The prevalence of depression in CM-1 patients has been poorly studied, with very few reports in the literature. According to interviews with parents of 86 children with CM-1 and a review of complementary medical record data, Lacy et al. reported a $10.5 \%$ prevalence of depression in pediatric CM-1 patients. ${ }^{16}$ An analysis of the national Conquer Chiari Patient Registry database reported a $32 \%$ prevalence of depression among 768 CM-1 patients, but the data were based on patientreported symptoms and diagnostic experiences recorded through questionnaires. ${ }^{17}$ In our surgical cohort of adult CM-1 patients, a depression prevalence of $28 \%$ was found. Although epidemiological studies in this patient population are still lacking, depression appears to be much more common among CM-1 patients than the general patient population. Several factors may help explain this finding. CM-1 is more common in female patients, ${ }^{18}$ who are known to have higher rates of depression. Additionally, the clinical symptomatology of CM-1 and resulting impairment in quality of life may play a role in bringing about depression. Interestingly, the cerebellum has been shown to be involved in emotion regulation circuits, ${ }^{19}$ and cerebellar changes have been linked to mood disorders in both structural ${ }^{20,21}$ and functional ${ }^{22,23}$ studies. Further investigation may help determine whether the disease process itself, including cerebellar tonsillar compression, contributes to mood dysregulation apart from the impairment 
TABLE 1. Baseline characteristics of adult CM-1 patients with and without depression

\begin{tabular}{|c|c|c|c|}
\hline Characteristic & Depression $(n=41)$ & No Depression $(n=108)$ & $\mathrm{p}$ Value \\
\hline Age at diagnosis, yrs & $33.7 \pm 12.4$ & $35.6 \pm 11.2$ & 0.369 \\
\hline BMI, $\mathrm{kg} / \mathrm{m}^{2}(\mathrm{n}=147)^{*}$ & $29.6 \pm 7.7$ & $31.3 \pm 8.5$ & 0.276 \\
\hline Sex & & & 0.247 \\
\hline Female & $36(88)$ & $86(80)$ & \\
\hline Male & $5(12)$ & $22(20)$ & \\
\hline Race & & & 0.351 \\
\hline White & $32(78)$ & $70(65)$ & \\
\hline Black & $7(17)$ & $27(25)$ & \\
\hline Other & $2(5)$ & $11(10)$ & \\
\hline Family history of CM-1 & $5(12)$ & $6(6)$ & 0.176 \\
\hline Trauma history & $7(17)$ & $23(21)$ & 0.566 \\
\hline Analgesic use & $32(78)$ & $86(80)$ & 0.832 \\
\hline Narcotic intake & $5(12)$ & $22(20)$ & 0.247 \\
\hline CSI grade & & & 0.482 \\
\hline 1 & $18(44)$ & $60(56)$ & \\
\hline 2 & $20(49)$ & $41(38)$ & \\
\hline 3 & $3(7)$ & $7(6)$ & \\
\hline \multicolumn{4}{|l|}{ Radiological variables } \\
\hline Syrinx present & $7(17)$ & $32(30)$ & 0.119 \\
\hline Tonsillar ectopia, mm & $8.5 \pm 3.7$ & $9.5 \pm 4.8$ & 0.239 \\
\hline Peg-shaped tonsils & $16(39)$ & $52(48)$ & 0.318 \\
\hline Symptom duration, yrs $(n=145)^{*}$ & $3.6 \pm 4.5$ & $3.9 \pm 5.6$ & 0.753 \\
\hline \multicolumn{4}{|l|}{ Clinical presentation } \\
\hline Headache & $39(95)$ & $102(94)$ & 0.999 \\
\hline Valsalva headache & $25(61)$ & $66(61)$ & 0.988 \\
\hline Occipital headache $(n=141) \dagger$ & $25(64)$ & $58(57)$ & 0.435 \\
\hline Neck pain & $28(68)$ & $75(69)$ & 0.892 \\
\hline Numbness & $23(56)$ & $63(58)$ & 0.805 \\
\hline Paresthesias & $28(68)$ & $64(59)$ & 0.311 \\
\hline Syncope & $6(15)$ & $11(10)$ & 0.564 \\
\hline Concentration disturbance & $23(56)$ & $52(48)$ & 0.386 \\
\hline Memory issues & $9(22)$ & $21(19)$ & 0.733 \\
\hline Hearing problems & $5(12)$ & $11(10)$ & 0.769 \\
\hline Tinnitus & $19(46)$ & $36(33)$ & 0.142 \\
\hline Visual problems & $23(56)$ & $44(41)$ & 0.092 \\
\hline Dysphagia & $19(46)$ & $38(35)$ & 0.211 \\
\hline Dizziness & $30(73)$ & $56(52)$ & $0.019 \ddagger$ \\
\hline Vertigo & $10(24)$ & $16(15)$ & 0.169 \\
\hline Nausea/vomiting & $18(45)$ & $39(36)$ & 0.382 \\
\hline Imbalance & $33(81)$ & $64(60)$ & $0.015 \ddagger$ \\
\hline Weakness & $12(29)$ & $22(20)$ & 0.248 \\
\hline Speech disturbance & $10(24)$ & $23(21)$ & 0.685 \\
\hline Fatigue & $17(42)$ & $33(31)$ & 0.208 \\
\hline Hyperactive reflexes & $3(7)$ & $4(4)$ & 0.394 \\
\hline Gait disturbance & $7(17)$ & $12(11)$ & 0.330 \\
\hline
\end{tabular}

Categorical variables are presented as number (\%) and continuous variables as mean $\pm \mathrm{SD}$.

* Sample sizes refer to number without missing data.

† Recorded for 141 patients with positive headache on presentation.

$\ddagger$ Statistically significant. 


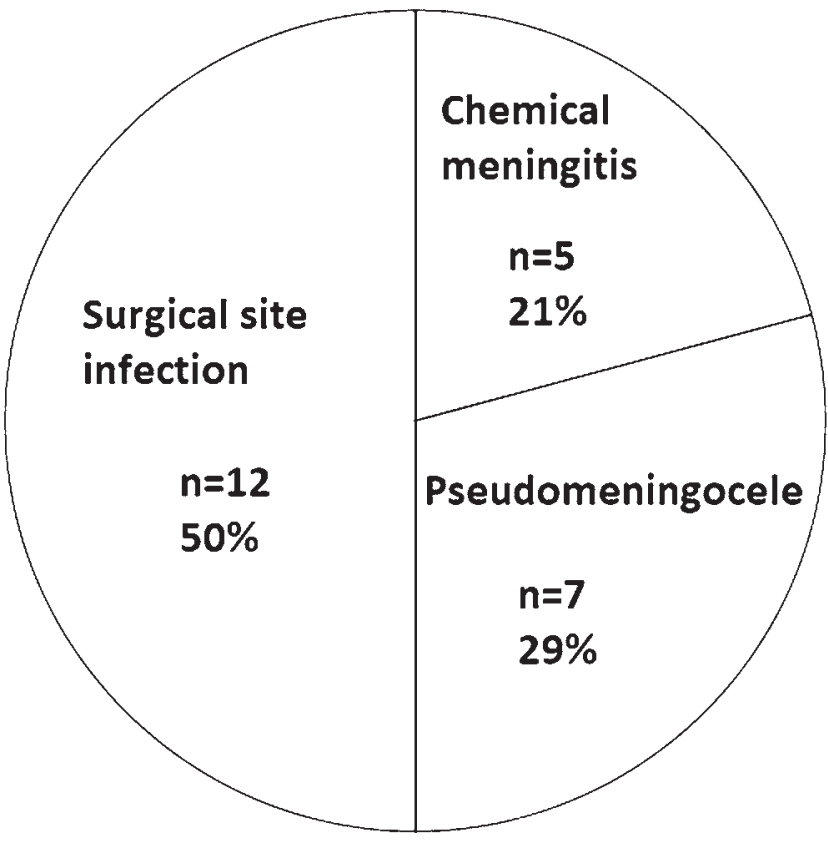

FIG. 1. Pie chart summarizing postoperative complications in the study patients.

caused by CM-1 symptoms. Since the symptoms of CM-1 are nonspecific, consisting of headaches, weakness, numbness, clumsiness, and fatigue, some patients may receive psychiatric diagnoses that delay investigation for CM-1, which further complicates the relationship between depression and CM-1. In one study, Milhorat et al. reported that $59 \%$ of CM-1 patients had been told by at least one physician that they suffered from a psychogenic disorder by the time they were diagnosed. ${ }^{24}$ This might partially explain the long time period between the first physician visit and diagnosis, which was estimated to be around 3.43 years in the national Conquer Chiari Patient Registry database. ${ }^{17}$ Similarly, our study found an average delay of 3.8 years from the start of noticeably impairing symptoms until diagnosis.

\section{Depression and Outcome in Neurological Disease}

The link between depression and poor outcome has been identified in several neurological diseases, including cerebrovascular-, spine-, and tumor-related pathologies. Aside from being an independent risk factor for stroke, ${ }^{6}$ depression has been linked to increased all-cause mortality after stroke, with an adjusted hazard ratio of $1.89 .{ }^{25} \mathrm{De}-$ pression has also been found to be an independent predictor of poor quality of life 1 year after subarachnoid hemorrhage. ${ }^{26}$ In addition, in a query of the Quality and Outcomes Database for patients undergoing elective lumbar surgery for degenerative disease, depression was significantly associated with surgery-related readmission during the 3-month postoperative period. ${ }^{27}$ In another analysis, patients with preoperative depression had less improvement in postoperative quality of life outcomes following posterior cervical fusion. ${ }^{28}$ On a larger scale, depression has been found to be a predictor of disease progression and mortality in cancer patients in general. ${ }^{29}$ It has also been heavily investigated specifically in relation to outcomes in glioma patients. ' Associations between depression and poor long-term survival have been described in both low-grade ${ }^{30}$ and high-grade ${ }^{31,32}$ glioma patients, and depression was found to be strongly associated with postoperative fatigue in a prospective evaluation of glioblastoma patients. ${ }^{33}$ Analogously, depression was reported to be significantly associated with pain persistence and dissatisfaction with outcome after microvascular decompression in trigeminal neuralgia patients. ${ }^{34,35}$

\section{Depression and Outcome in CM-1}

In accordance with the previous studies described above, our study provides evidence that depression is independently associated with poor surgical outcome in adult CM-1 patients, specifically according to our evalu-

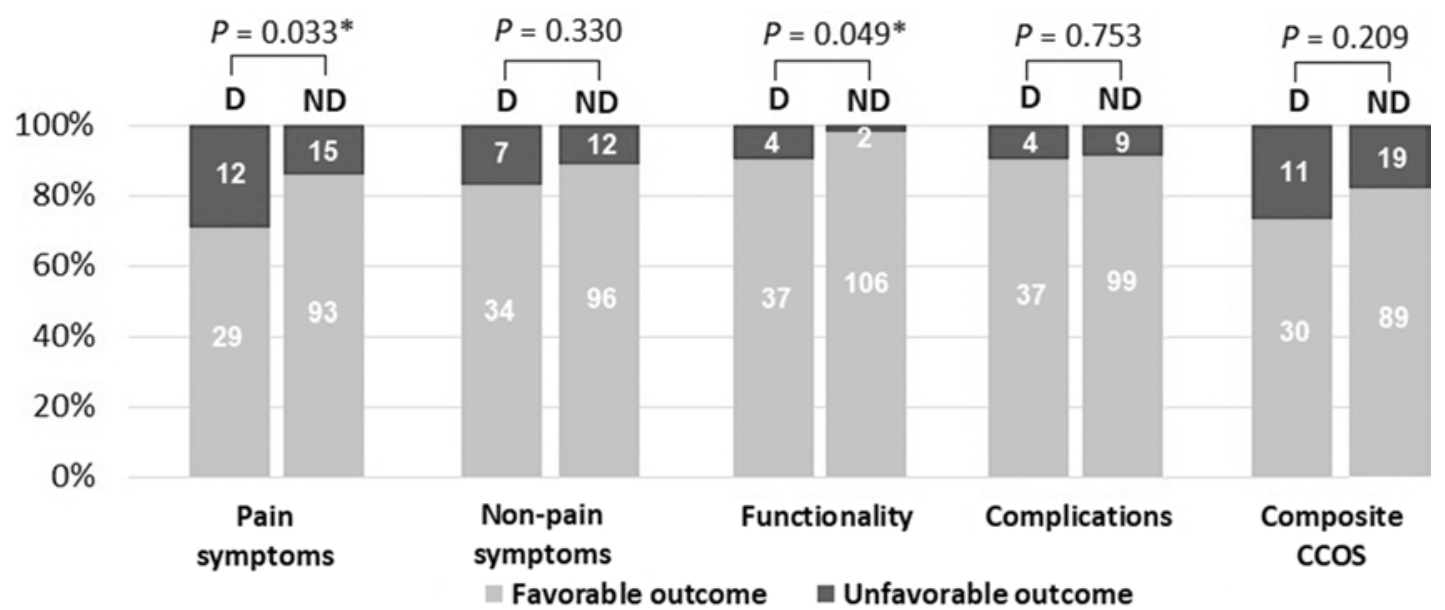

FIG. 2. Outcomes across the CCOS composite and subcomponent scores in depressed (D) and nondepressed (ND) patients. Values indicate the number of patients in each outcome category. *Statistically significant. 
TABLE 2. Univariable analysis of factors associated with poor outcome as measured by the CCOS

\begin{tabular}{|c|c|c|c|c|c|c|c|c|c|c|}
\hline \multirow[b]{2}{*}{ Characteristic* } & \multicolumn{2}{|c|}{$\begin{array}{c}\text { Pain } \\
\text { Improvement }\end{array}$} & \multicolumn{2}{|c|}{$\begin{array}{c}\text { Nonpain Symptom } \\
\text { Improvement }\end{array}$} & \multicolumn{2}{|c|}{$\begin{array}{l}\text { Functionality } \\
\text { Improvement }\end{array}$} & \multicolumn{2}{|c|}{$\begin{array}{c}\text { Complications } \\
\text { (none or transient) }\end{array}$} & \multicolumn{2}{|c|}{$\begin{array}{c}\text { Composite CCOS } \\
\text { Improvement } †\end{array}$} \\
\hline & OR & $p$ Value & OR & p Value & OR & $p$ Value & OR & $p$ Value & OR & $p$ Value \\
\hline Depression & 0.39 & $0.033 \S$ & 0.61 & 0.330 & 0.17 & $0.049 \S$ & 0.84 & 0.753 & 0.58 & 0.209 \\
\hline Age (per yr) & 1.01 & 0.669 & 0.97 & 0.106 & 0.98 & 0.580 & 0.99 & 0.658 & 0.98 & 0.166 \\
\hline Symptom duration (per yr) & 1.01 & 0.881 & 1.01 & 0.915 & 0.97 & 0.595 & 1.31 & 0.083 & 1.03 & 0.520 \\
\hline BMI (per kg/m²) & 1.05 & 0.089 & 1.01 & 0.764 & 0.99 & 0.765 & 1.05 & 0.186 & 1.04 & 0.150 \\
\hline Sex (female vs male) & 1.03 & 0.953 & 1.24 & 0.751 & 4.96 & 0.073 & 0.81 & 0.999 & 1.17 & 0.765 \\
\hline Race (white vs other) $\ddagger$ & 0.14 & $0.003 \S$ & 0.54 & 0.292 & - & 0.177 & 1.40 & 0.549 & 0.37 & 0.050 \\
\hline Dizziness & 1.34 & 0.496 & 0.77 & 0.607 & 0.67 & 0.999 & 1.19 & 0.767 & 1.06 & 0.896 \\
\hline Imbalance & 1.12 & 0.797 & 0.84 & 0.745 & 0.36 & 0.665 & 0.81 & 0.999 & 1.10 & 0.820 \\
\hline Syrinx & 0.81 & 0.652 & 0.74 & 0.582 & 0.70 & 0.652 & 0.53 & 0.326 & 0.53 & 0.144 \\
\hline Ectopia (per mm) & 1.02 & 0.671 & 1.01 & 0.903 & 0.96 & 0.540 & 0.94 & 0.280 & 0.99 & 0.953 \\
\hline Peg-shaped tonsils & 0.51 & 0.116 & 0.57 & 0.251 & 0.41 & 0.412 & 0.13 & $0.003 \S$ & 0.48 & 0.077 \\
\hline CSI grade & & 0.660 & & 0.068 & & 0.540 & & 0.976 & & 0.301 \\
\hline 2 vs 1 & 0.67 & 0.368 & 0.28 & $0.024 \S$ & 0.38 & 0.267 & 1.10 & 0.871 & 0.56 & 0.177 \\
\hline 3 vs $1 \ddagger$ & 0.73 & 0.708 & 0.27 & 0.157 & - & 0.999 & 0.89 & 0.915 & 0.42 & 0.258 \\
\hline
\end{tabular}

* Odds ratios for binary variables are expressed as present versus absent.

† Defined as a total score of 13-16.

$\ddagger$ None of the nonwhite patients or CSI grade 3 patients demonstrated lack of functional improvement and hence the OR could not be expressed mathematically.

$\S$ Statistically significant.

ation of improvement in pain symptoms and functionality. The interaction between depression and pain has been well documented and has been labeled as the "depressionpain syndrome" by some authors. ${ }^{36}$ These two conditions often exacerbate one another and have been shown to share biological pathways and neurotransmitters. ${ }^{37} \mathrm{~A}$ review by Bair et al. demonstrated that depressed patients often have more pain complaints, more severe pain, and longer duration of pain symptoms.$^{38}$ Headache is the most common symptom reported in CM-1 patients, ${ }^{39}$ and similar associations between depression and worse pain have been specifically reported in chronic tension headache patients. ${ }^{40}$ Since clinically significant distress or impairment in different areas of functioning is part of the DSM definition for depression, less improvement in functionality after surgery was expected in the CM-1 patients with

TABLE 3. Multivariable analysis of factors associated with poor outcome as measured by the CCOS

\begin{tabular}{|c|c|c|c|c|c|c|c|c|c|c|}
\hline \multirow[b]{2}{*}{ Characteristic $^{*}$} & \multicolumn{2}{|c|}{$\begin{array}{c}\text { Pain } \\
\text { Improvement }\end{array}$} & \multicolumn{2}{|c|}{$\begin{array}{c}\text { Nonpain Symptom } \\
\text { Improvement }\end{array}$} & \multicolumn{2}{|c|}{$\begin{array}{l}\text { Functionality } \\
\text { Improvement }\end{array}$} & \multicolumn{2}{|c|}{$\begin{array}{c}\text { Complications } \\
\text { (none or transient) }\end{array}$} & \multicolumn{2}{|c|}{$\begin{array}{l}\text { Composite CCOS } \\
\text { Improvement } \dagger\end{array}$} \\
\hline & OR & $p$ Value & OR & $p$ Value & OR & $p$ Value & OR & $p$ Value & OR & p Value \\
\hline Depression & 0.36 & $0.044 \S$ & 0.51 & 0.257 & 0.05 & $0.026 \S$ & 0.58 & 0.489 & 0.50 & 0.164 \\
\hline Age (per year) & 1.00 & 0.886 & 0.97 & 0.191 & 0.96 & 0.364 & 0.99 & 0.931 & 0.97 & 0.152 \\
\hline Symptom duration (per yr) & 1.01 & 0.892 & 1.01 & 0.905 & 0.92 & 0.507 & 1.40 & 0.055 & 1.04 & 0.432 \\
\hline BMI (per kg/m²) & 1.04 & 0.311 & 0.98 & 0.634 & 0.91 & 0.221 & 1.06 & 0.183 & 1.03 & 0.363 \\
\hline Sex (female vs male) & 1.15 & 0.824 & 1.91 & 0.343 & 14.22 & $0.031 \S$ & 0.78 & 0.784 & 1.54 & 0.459 \\
\hline Race (white vs other) $\ddagger$ & 0.16 & $0.023 \S$ & 0.61 & 0.468 & - & 0.997 & 1.43 & 0.633 & 0.33 & 0.072 \\
\hline Syrinx & 0.38 & 0.123 & 0.67 & 0.572 & 0.13 & 0.156 & 0.64 & 0.605 & 0.33 & 0.056 \\
\hline Peg-shaped tonsils & 0.49 & 0.139 & 0.55 & 0.290 & 0.37 & 0.469 & 0.11 & $0.009 \S$ & 0.52 & 0.154 \\
\hline CSI grade & & 0.650 & & 0.210 & & 0.936 & & 0.773 & & 0.635 \\
\hline 2 vs 1 & 0.78 & 0.631 & 0.34 & 0.078 & 0.62 & 0.716 & 0.97 & 0.964 & 0.70 & 0.455 \\
\hline 3 vs $1 \ddagger$ & 2.04 & 0.521 & 0.41 & 0.435 & - & 0.999 & 2.70 & 0.519 & 1.41 & 0.727 \\
\hline
\end{tabular}

* Odds ratios for binary variables are expressed as present versus absent.

$\dagger$ Defined as a total score of 13-16.

$\ddagger$ None of the nonwhite patients or CSI grade 3 patients demonstrated lack of functional improvement and hence the OR could not be expressed mathematically. $\S$ Statistically significant. 
depression in our study. It is also important to note that depression may manifest with several somatic symptoms such as headache and weakness; ${ }^{41}$ hence, such symptoms may be more resistant to improvement following surgery in a depressed patient. Based on these findings, one can appreciate the importance of evaluating for and diagnosing depression and comorbid psychiatric illness in adult CM-1 patients. An analysis using a nationwide sample of adult CM-1 patients indicated high rates of depression (44\%) regardless of the history of suboccipital decompression and suggested that CM-1 patients would benefit from evidence-based interventions addressing depressive symptoms. ${ }^{42}$ Optimizing the management of depression preoperatively and ensuring follow-up for psychiatric comorbidity in the postoperative period may possibly lead to improved outcomes after decompression, but studies are still needed in this regard. Multidisciplinary crosstalk between treating neurosurgeons and psychiatrists in certain depressed patients with profound mood symptoms and suspected somatization may improve patient selection for surgery and outcomes. It may even be worthwhile to take note of comorbid depression in patients participating in future clinical trials evaluating the efficacy of different management approaches in treating CM-1, as it may represent an important confounder.

\section{Study Limitations}

This study has many limitations, and the results should be interpreted with caution. This is a single-center study, so the generalizability of the results remains unclear. The demographics of our surgical cohort closely resembled those of a population-wide study on 1947 CM-1 patients undergoing surgery in the United States, which was composed mostly of female $(81 \%)$ and white $(63 \%)$ patients. ${ }^{43}$ These demographics also resembled those of a surgical cohort in France, in which patients had an average age of 37 years at diagnosis and a female to male ratio of $80 \%{ }^{4}$ These similarities do not exclude the presence of selection bias but do lend greater confidence to our results. Another limitation of the present study is the assessment of depression, a commonly underdiagnosed disease, ${ }^{44,45}$ in a retrospective manner. It could not be confirmed that all patients had the necessary psychiatric assessment before obtaining the diagnosis of depression. In addition, the severity of the depression and the extent to which it had been effectively controlled could not be assessed. Ideally, in future studies a prospective study design that includes a formal preoperative psychiatric assessment can more definitively detemine whether severity of depression impacts outcome in CM-1 patients. Larger sample sizes with larger proportions of depressed patients can also more effectively identify possible differences that are more subtle, such as favorable outcomes in nonpain symptoms and overall CCOS.

\section{Conclusions}

In summary, we have provided preliminary evidence that depression is independently associated with lower rates of favorable improvement in pain symptoms and functionality following decompression surgery in adult
CM-1 patients. Further prospective studies are still needed to clearly delineate the relationship between depression and CM-1 presentation and outcome.

\section{References}

1. Chiari H. Über veränderungen des kleinhirns infolge von hydrocephalie des grosshirns. Dtsch Med Wochenschr. 1891;17:1172-1175.

2. Meadows J, Kraut M, Guarnieri M, et al. Asymptomatic Chiari Type I malformations identified on magnetic resonance imaging. J Neurosurg. 2000;92(6):920-926.

3. Haines SJ, Berger M. Current treatment of Chiari malformations types I and II: a survey of the Pediatric Section of the American Association of Neurological Surgeons. Neurosurgery. 1991;28(3):353-357.

4. Grangeon L, Puy L, Gilard V, et al. Predictive factors of headache resolution after Chiari type 1 malformation surgery. World Neurosurg. 2018;110:e60-e66.

5. Thakar S, Sivaraju L, Jacob KS, et al. A points-based algorithm for prognosticating clinical outcome of Chiari malformation Type I with syringomyelia: results from a predictive model analysis of 82 surgically managed adult patients. $J$ Neurosurg Spine. 2018;28(1):23-32.

6. Pan A, Sun Q, Okereke OI, et al. Depression and risk of stroke morbidity and mortality: a meta-analysis and systematic review. JAMA. 2011;306(11):1241-1249.

7. Rooney AG, Brown PD, Reijneveld JC, Grant R. Depression in glioma: a primer for clinicians and researchers. J Neurol Neurosurg Psychiatry. 2014;85(2):230-235.

8. Luciano MG, Batzdorf U, Kula RW, et al. Development of Common Data Elements for use in Chiari malformation type I clinical research: an NIH/NINDS project. Neurosurgery. 2019;85(6):854-860.

9. Doktorchik C, Patten S, Eastwood C, et al. Validation of a case definition for depression in administrative data against primary chart data as a reference standard. BMC Psychiatry. 2019;19(1):9.

10. Greenberg JK, Yarbrough CK, Radmanesh A, et al. The Chiari Severity Index: a preoperative grading system for Chiari malformation type 1. Neurosurgery. 2015;76(3):279-285.

11. Aliaga L, Hekman KE, Yassari R, et al. A novel scoring system for assessing Chiari malformation type I treatment outcomes. Neurosurgery. 2012;70(3):656-665.

12. Greenberg JK, Milner E, Yarbrough CK, et al. Outcome methods used in clinical studies of Chiari malformation Type I: a systematic review. J Neurosurg. 2015;122(2):262-272.

13. Yarbrough CK, Greenberg JK, Park TS. Clinical outcome measures in Chiari I malformation. Neurosurg Clin N Am. 2015;26(4):533-541.

14. Lim GY, Tam WW, Lu Y, et al. Prevalence of depression in the community from 30 countries between 1994 and 2014. Sci Rep. 2018;8(1):2861.

15. Hasin DS, Sarvet AL, Meyers JL, et al. Epidemiology of adult DSM-5 major depressive disorder and its specifiers in the United States. JAMA Psychiatry. 2018;75(4):336-346.

16. Lacy M, DeDios-Stern S, Fredrickson S, et al. Prevalence of psychiatric diagnoses in pediatric Chiari malformation type 1. Pediatr Neurosurg. 2018;53(6):371-378.

17. Fischbein R, Saling JR, Marty P, et al. Patient-reported Chiari malformation type I symptoms and diagnostic experiences: a report from the national Conquer Chiari Patient Registry database. Neurol Sci. 2015;36(9):1617-1624.

18. Krucoff MO, Cook S, Adogwa O, et al. Racial, socioeconomic, and gender disparities in the presentation, treatment, and outcomes of adult Chiari I malformations. World Neurosurg. 2017;97:431-437.

19. Schmahmann JD, Sherman JC. The cerebellar cognitive affective syndrome. Brain. 1998;121(Pt 4):561-579. 
20. Brambilla P, Harenski K, Nicoletti M, et al. MRI study of posterior fossa structures and brain ventricles in bipolar patients. J Psychiatr Res. 2001;35(6):313-322.

21. Pillay SS, Yurgelun-Todd DA, Bonello CM, et al. A quantitative magnetic resonance imaging study of cerebral and cerebellar gray matter volume in primary unipolar major depression: relationship to treatment response and clinical severity. Biol Psychiatry. 1997;42(2):79-84.

22. Kimbrell TA, Ketter TA, George MS, et al. Regional cerebral glucose utilization in patients with a range of severities of unipolar depression. Biol Psychiatry. 2002;51(3):237-252.

23. Liotti M, Mayberg HS, McGinnis S, et al. Unmasking disease-specific cerebral blood flow abnormalities: mood challenge in patients with remitted unipolar depression. Am J Psychiatry. 2002;159(11):1830-1840.

24. Milhorat TH, Chou MW, Trinidad EM, et al. Chiari I malformation redefined: clinical and radiographic findings for 364 symptomatic patients. Neurosurgery. 1999;44(5):1005-1017.

25. Jørgensen TSH, Wium-Andersen IK, Wium-Andersen MK, et al. Incidence of depression after stroke, and associated risk factors and mortality outcomes, in a large cohort of Danish patients. JAMA Psychiatry. 2016;73(10):1032-1040.

26. Taufique Z, May T, Meyers E, et al. Predictors of poor quality of life 1 year after subarachnoid hemorrhage. Neurosurgery. 2016;78(2):256-264.

27. Sivaganesan A, Zuckerman S, Khan I, et al. Predictive model for medical and surgical readmissions following elective lumbar spine surgery: a national study of 33,674 patients. Spine (Phila Pa 1976). 2019;44(8):588-600.

28. Alvin MD, Miller JA, Sundar S, et al. The impact of preoperative depression on quality of life outcomes after posterior cervical fusion. Spine J. 2015;15(1):79-85.

29. Satin JR, Linden W, Phillips MJ. Depression as a predictor of disease progression and mortality in cancer patients: a metaanalysis. Cancer. 2009;115(22):5349-5361.

30. Mainio A, Tuunanen S, Hakko H, et al. Decreased quality of life and depression as predictors for shorter survival among patients with low-grade gliomas: a follow-up from 1990 to 2003. Eur Arch Psychiatry Clin Neurosci. 2006;256(8):516521.

31. Gathinji M, McGirt MJ, Attenello FJ, et al. Association of preoperative depression and survival after resection of malignant brain astrocytoma. Surg Neurol. 2009;71(3):299-303.

32. Litofsky NS, Farace E, Anderson F Jr, et al. Depression in patients with high-grade glioma: results of the Glioma Outcomes Project. Neurosurgery. 2004;54(2):358-367.

33. Valko PO, Siddique A, Linsenmeier C, et al. Prevalence and predictors of fatigue in glioblastoma: a prospective study. Neuro Oncol. 2015;17(2):274-281.

34. Chang B, Zhu W, Li S. Effects of depression and anxiety on microvascular decompression outcome for trigeminal neuralgia patients. World Neurosurg. 2019;128:e556-e561.

35. Mousavi SH, Sekula RF, Gildengers A, et al. Concomitant depression and anxiety negatively affect pain outcomes in surgically managed young patients with trigeminal neuralgia: long-term clinical outcome. Surg Neurol Int. 2016;7:98.
36. Lindsay PG, Wyckoff M. The depression-pain syndrome and its response to antidepressants. Psychosomatics. 1981;22(7):571-573, 576-577.

37. Blier P, Abbott FV. Putative mechanisms of action of antidepressant drugs in affective and anxiety disorders and pain. $J$ Psychiatry Neurosci. 2001;26(1):37-43.

38. Bair MJ, Robinson RL, Katon W, Kroenke K. Depression and pain comorbidity: a literature review. Arch Intern Med. 2003;163(20):2433-2445.

39. Nohria V, Oakes WJ. Chiari headaches. Neurology. 1993;43(6):1272.

40. Holroyd KA, Stensland M, Lipchik GL, et al. Psychosocial correlates and impact of chronic tension-type headaches. Headache. 2000;40(1):3-16.

41. Simon GE, VonKorff M, Piccinelli M, et al. An international study of the relation between somatic symptoms and depression. N Engl J Med. 1999;341(18):1329-1335.

42. Garcia MA, Allen PA, Li X, et al. An examination of pain, disability, and the psychological correlates of Chiari Malformation pre- and post-surgical correction. Disabil Health J. 2019;12(4):649-656.

43. Greenberg JK, Ladner TR, Olsen MA, et al. Complications and resource use associated with surgery for Chiari malformation type 1 in adults: a population perspective. Neurosurgery. 2015;77(2):261-268.

44. Bell JR. Underdiagnosis of depression in primary care: by accident or design? JAMA. 1997;277(18):1433.

45. Licht-Strunk E, Van Marwijk HWJ, Hoekstra T, et al. Outcome of depression in later life in primary care: longitudinal cohort study with three years' follow-up. $B M J$. 2009;338:a3079.

\section{Disclosures}

Dr. Judy Huang declares stock ownership interest in Longeviti Neuro Solutions.

\section{Author Contributions}

Conception and design: all authors. Acquisition of data: Feghali, Y Chen, Xie, C Chen. Analysis and interpretation of data: Feghali. Drafting the article: all authors. Critically revising the article: Huang, Feghali, Y Chen, Xie. Reviewed submitted version of manuscript: all authors. Approved the final version of the manuscript on behalf of all authors: Huang. Statistical analysis: Feghali. Study supervision: Huang.

\section{Correspondence}

Judy Huang: Johns Hopkins University School of Medicine, Baltimore, MD. jhuang24@jhmi.edu. 